\title{
Nanofiber Electrospinning Combined with Rotary Bioprinting for Fabricating Small-Diameter Vessels with Endothelium and Smooth Muscle
}

Qianheng Jin

Ruihua Hospital Affiliated to Soochow University

Yi Fu

Department of Human Anatomy, Histology and Embryology, School of Biology and Basic Medical

Sciences, Soochow University

Guangliang Zhang

Ruihua Hospital Affiliated to Soochow University

Lei Xu

Ruihua Hospital Affiliated to Soochow University

\section{Guangzhe Jin}

Ruihua Hospital Affiliated to Soochow University

\section{Linfeng Tang}

Ruihua Hospital Affiliated to Soochow University

Jihui Ju

Soochow University Affiliated No 1 Peoplel's Hospital: First Affiliated Hospital of Soochow University

Weixin Zhao

Wake Forest Institute for Regenerative Medicine

Ruixing Hou ( $\sim$ hrx2020@suda.edu.cn )

Ruihua Hospital Affiliated to Soochow University

\section{Research}

Keywords: Small-diameter bionic vascular vessel, Nanofiber electrospinning, Rotary bioprinting, Tissue engineering, Cardiovascular disease

Posted Date: September 7th, 2021

DOI: https://doi.org/10.21203/rs.3.rs-861389/v1

License: (c) (i) This work is licensed under a Creative Commons Attribution 4.0 International License.

Read Full License 
Version of Record: A version of this preprint was published at Composites Part B: Engineering on January 1st, 2022. See the published version at https://doi.org/10.1016/j.compositesb.2022.109691. 


\section{Nanofiber electrospinning combined with rotary bioprinting for fabricating}

\section{small-diameter vessels with endothelium and smooth muscle}

Qianheng Jin ${ }^{1,2,3 \dagger}$, Yi Fu ${ }^{4 \dagger}$, Guangliang Zhang ${ }^{1,2,3 \dagger}$, Lei Xu ${ }^{1,2,3}$, Guangzhe Jin ${ }^{1,2}$, Linfeng Tang ${ }^{1,2}$, Jihui $\mathrm{Ju}^{1,2^{*}}$, Weixin $\mathrm{Zhao}^{3 *}$, Ruixing $\mathrm{Hou}^{1,2^{*}}$,

*Correspondece: hrx2020@suda.edu.cn; wezhao@wakehealth.edu; jjh2020@suda.edu.cn $†$ Qianheng Jin, Yi Fu, Guangliang Zhang contributed equally to this work 


\section{Abstract}

Background: Cardiovascular disease is responsible for a large number of deaths each year. Autologous vascular transplantation is still the best surgical intervention option, but the success rate is affected by many factors. Tissue engineering is a growing research area of great interest because it can produce bionic grafts to replace autologous tissue. Although many molding strategies have been tried, precellularization of small-diameter vascular grafts remains a research challenge. Here, a novel approach for fabricating bionic small-diameter vascular vessels with endothelial and smooth muscle cells is developed through combining nanofiber electrospinning and a specially-designed rotary bioprinter.

Results: Combining and utilizing the advantages of nanofiber electrospinning and rotary printing, a tissue-engineered vascular tissue more suitable for biological transplantation is fabricated. Electrospun poly( $\varepsilon$-caprolactone) (PCL) provides good elasticity, and the electrospinning modification is beneficial for adhesion and functionalization of endothelial cells. A flat monolayer on the surface of PCL is formed after 7 days cultivation. Modification of the traditional three-dimensional (3D) bioprinter to increase rotation of the central axis used dual motors rotating clockwise and anticlockwise at the same speed increase stability during the printing process. This allowed a uniform dense methacrylated gelatin (GelMA) structure containing smooth muscle cells to be bioprinted with the cells are arranged linearly along the horizontal axis of rotation. Perfused with umbilical vein endothelial cells, a monolayer endothelial structure is formed. The two type cells maintain viability and proliferation in the structure during the process of cultivation. In addition, the bionic structure 
is superior to the natural blood vessel in anti-burst pressure and suture retention strength.

Conclusion: By combining nanofiber electrospinning and modified rotary bioprinter, we successfully formed a small-diameter bionic vascular vessel with smooth muscle cells and endothelial cells. This method takes advantages of two advanced technologies and provides a new strategy for the development of bionic blood vascular tissue.

Keywords: Small-diameter bionic vascular vessel; Nanofiber electrospinning; Rotary bioprinting; Tissue engineering; Cardiovascular disease 


\section{Background}

Cardiovascular diseases (CVDs) are common diseases and difficult to treat in clinic. The World Health Organization (WHO) indicates that CVDs are the leading cause of death globally ${ }^{1,2}$. When pharmaceuticals are ineffective in treating these diseases, surgical treatment is the only option, with autologous blood vessel transplantation is the gold standard in surgery ${ }^{3}$. However, due to the need for an invasive operation at the donor site and the potential complications, the application of blood vessel transplantation is limited in clinical practice $^{4,5}$. For large diameter vessels, synthetic grafts are an effective substitute ${ }^{6}$. Dacron and expanded polytetrafluoroethylene (ePTFE) are clinically applied in reconstruction of vascular defects and perform well as large diameter conduits ${ }^{4}$. However, due to thrombosis, plaque deposition caused by stenosis or occlusion, and mechanical mismatch, their application in small-diameter blood vessels (SDBVs; $<6 \mathrm{~mm}$ ) is limited ${ }^{7,8}$. Therefore, replacing natural small-diameter vessels using synthetic materials remains an unmet challenge ${ }^{9}$.

Tissue engineering is an excellent strategy toward solving this problem because it can combine materials and cells organically ${ }^{10,11} .3 \mathrm{D}$ bioprinting is an advanced tissue engineering technology with potential to manufacture of SDBVs due to the precise spatial control of materials and cells ${ }^{12,13}$. Using catechol-functionalized, gelatin methacrylate (GelMA/C) containing smooth muscle cells (SMCs) as the outer layer and Pluronic F127 containing $\mathrm{Ca}^{2+}$ and human umbilical vein endothelial cells (HUVECs) as the inner layer, an elastic hydrogel can be formed by rapid oxidative crosslinking during the coaxial bioprinting progress. In vivo and in vitro experiments indicate that the structure has good activity and 
compatibility ${ }^{14}$. Although, hydrogels (such as fibrin, gelatin, alginate) used in bioprinting have good biocompatibility, poor mechanical strength makes it impossible to simulate the suture resistance of real blood vessels ${ }^{15}$. In addition, the surface of the hydrogel needs to be pretreated to facilitate the attachment and functionalization of endothelial cells ${ }^{16} .3 \mathrm{D}$ bioprinting is thus limited for transplantation of small diameter blood vessels.

Electrospinning is another effective method to construct SDBVs ${ }^{17}{ }^{18}$. Proper surface modification is key to promoting cell adhesion, growth and rapid reendothelialization ${ }^{14,19}$. Electrospinning is an effective surface modification and cost effective technology ${ }^{20}$. Under the electrostatic driving process, material is plasticized into nanofibers with high specific surface area, good mechanical properties and suitable porosity ${ }^{21}$. The electrospun matrix has shown promise as an effective vascular tissue engineering approach, as tunable porosity and extremely high surface to volume ratio mimic that of the extracellular matrix (ECM) of native vessels, promoting cellular activities including proliferation and differentiation ${ }^{6}$. However, electrospinning can only make vascular grafts endothelialized through the perfusion of endothelial cells and cannot simulate the vascular middle (smooth muscle cells) layer. The graft can only be muscularized by a later crawling replacement that is limited in large segment vascular defects ${ }^{22}$.

Thus, there are many ways to manufacture SDBVs and each of these methods has their own advantages and limitations. Combining two or more technologies and combining their respective advantages can effectively compensate for their respective shortcomings to create tissue-engineered blood vessels with both excellent mechanical and biological properties ${ }^{23}$. In this study, we present a new approach for biofabricating SDBVs by combining 
electrospinning and modified 3D printer with clockwise and counterclockwise rotating dual motors. We shape PCL into scaffolds by electrospinning to improve the strength and elasticity of the whole structure and to enhance the adhesion and functionalization of endothelial cells. The GelMA-based bioink containing SMCs can be evenly distributed in the outer layer by the rotary bioprinter while the stability of small-diameter circular mandrel can be ensured using the double motors during the bioprinting process. In this way, we successfully constructed precellular SDBVs and the combination of these two advanced technologies represents a new step for the clinical transformation of tissue engineering biomimetic blood vessels.

\section{Results}

\section{Synthesis and identification of GelMA}

Gelatin and methacrylic acid reacted to produce GelMA with photo-crosslinking ability.

The reaction was identified by ${ }^{1} \mathrm{H}-\mathrm{Nuclear}$ Magnetic Resonance $\left({ }^{1} \mathrm{H}-\mathrm{NMR}\right)$. We observed the characteristic resonance peak of the double bond appear at 5.5-6.0 ppm in GelMA (Figure S1). The methacrylation degree of GelMA was $78.9 \pm 3.1 \%$ using TNBS.

\section{Characterization of electrospun PCL tubes}

PCL tubes with an inner diameter of $1.62 \mathrm{~mm}$ were fabricated by electrospinning. The mean wall thickness of all samples was $0.31 \mathrm{~mm}$ (Fig. 2a). Using a scanning electron microscope (SEM), nanofiber width was measured as $1.055 \pm 0.1382 \mu \mathrm{m}$ (Fig. 2b). To show the ductility of electrospun PCL, the same thickness of PCL without electrospinning treatment was used as a control. The control group could be extended by $145.5 \pm 5.043 \%$ while the electrospun group could be extended by $1384 \pm 76.22 \%$ (Fig. 2c). Ductility of 
polymer material was effectively increased by electrospinning.

\section{Properties of GelMA with different concentrations}

\section{Pore size}

Cell survival rate and proliferation were closely related to pore size of the structure. To identify the appropriate concentration of SMCs, scaffold samples were created using $2 \%, 5 \%$ and $8 \%$ GelMA solution and then observed at both macro (Fig. 2d) and micro (Fig. 2e) scales. After shaking in deionized water at $37^{\circ} \mathrm{C}$ for 2 days, uncrosslinked GelMA and other small molecules were removed and crosslinked GelMA expanded, resulting in an increase of pore size. Mean pore sizes were: $280.23 \pm 7.989 \mu \mathrm{m}(2 \%$ GelMA), $86.71 \pm 4.152 \mu \mathrm{m}(5 \%$ GelMA), and $52.44 \pm 2.810 \mu \mathrm{m}(8 \%$ GelMA) (Fig. 2f). Pore size of the scaffold was not affected by gelatin, glycerin, photo-crosslinking agent or hyaluronic acid (HA) in the GelMA solution. A pore size of $100 \mu \mathrm{m}$ maintained the SMCs in a stable space and promoted growth and function ${ }^{24}$. Therefore, we chose $5 \%$ GelMA as our printing concentration.

\section{Rheological measurement}

Physical properties were measured by oscillatory rheology. Storage modulus and loss modulus increased with increasing concentration of GelMA and remained stable for the various changes of angular frequency and strain tested. Storage modulus of the GelMA solution was much greater than its loss modulus and thus, GelMA maintained a stable solid state after crosslinking (Fig. 2g, h).

\section{Fabrication of acellular tubular structure}

A tubular structure with a GelMA scaffold as its outer layer and electrospun PCL as its 
inner layer was fabricated using rotary bioprinting and electrospinning. Thickness of the outer layer was $0.78 \mathrm{~mm}$, thickness of the electrospun PCL was $0.31 \mathrm{~mm}$, and the inner diameter was $1.62 \mathrm{~mm}$ (Fig. 3a). When the tubular structure was deformed via interior pressure, the structure recovered perfectly after the pressure was released, indicating good elasticity in the structure (Fig. 3b). The microstructure is shown in Figure 3c.

\section{Mechanical properties}

In general, burst pressure of the acellular tubular structure $(2035 \pm 173.8 \mathrm{mmHg})$ was higher than that of the average carotid artery $(1558 \pm 115.6 \mathrm{mmHg})$ (Fig. 3d). The structure was stiff enough to effectively resist the pulsation of blood flow. The tubular structure also had a much larger suture retention strength $(2.192 \pm 0.176 \mathrm{~N})$ than the normal carotid artery $(0.235 \pm 0.026 \mathrm{~N})$, indicating that the structure can be sutured (Fig. 3e).

\section{Growth situation of HUVECs on electrospun PCL}

Live/dead staining and fluorescence imaging was used to observe cell viability (Fig. 4a). Survival rate of HUVECs on the electrospun PCL at days 1, 4, and 7 was $87.64 \pm 1.38,91.57$ \pm 0.64 , and $97.38 \pm 0.35 \%$, respectively (Fig. 4b). HUVECs showed good viability after perfusion. The CCK-8 absorption value of HUVECs at days $0,1,4$ and 7 was $0.1618 \pm$ $0.0035,0.1634 \pm 0.0033,0.2510 \pm 0.0139$, and $0.3608 \pm 0.0114$, respectively (Fig. 4c). A good proliferation of HUVECs was detected on the electrospun membrane.

Microstructure of the HUVECs on the electrospun membrane was further observed by SEM. HUVECs were granular and scattered on the electrospun membrane at day 1. Some cells showed limited modality at day 4 . Cells were fused into pieces at day 7. After 7 days of cultivation. HUVECs formed a flat cell layer on the surface of the electrospun membrane. 


\section{Growth situation of SMCs in GelMA}

GelMA bioink containing SMCs was bioprinted. In this process, cells died partially due to a long separation time from the medium and stimulation from extrusion pressure. In our PCL structure, cells maintained a good survival rate (Fig. 5a) and over 90\% cell viability was observed in all groups (Fig. $5 b$ ). CCK-8 test absorption values were $0.1382 \pm 0.0107,0.1354$ $\pm 0.0076,0.2273 \pm 0.0154,0.3142 \pm 0.0193$ at days $0,1,4$, and 7 , respectively (Fig. 5c). SMCs were completely expanded in a linear shape and arranged in an orderly pattern along the printing direction at day 7 (Fig. 5d).

\section{Bionic vascular structure}

To show that the vessel-like structures with HUVECs and SMCs were formed by electrospinning and rotary printing, Masson staining was used to detect the morphology of the bionic tissue. After one week of culture, SMCs were evenly distributed in the outer layer of the GelMA scaffold and secreted collagen. The GelMA scaffold was tightly connected to the electrospun PCL and a circular monolayer of HUVECs was formed in the inner layer (Fig. 6a). Immunofluorescence staining further confirmed the good construction of bionic blood vessels with endothelial cells as the inner layer and smooth muscle cells as the outer layer (Fig. 6b).

\section{Discussion}

Tissue engineering has expanded possibilities for the research and development of vascular grafts. However, fabricating tissue engineered vascular grafts (TEVGs) with both advanced biological properties and suitable mechanical properties remains a challenge ${ }^{1}$. In this study, by treating the PCL with electrospinning, depositing the GelMA-SMCs bioink on 
the external layer and perfusing the HUVECs among the internal membrane, SDBVs with good biological and mechanical properties are successfully biofabricated by our novel approach.

PCL is a high polymer with superior biocompatibility that is biodegradable, has appropriate mechanical properties and is commonly used as the scaffold in vascular tissue engineering ${ }^{25}$. However, untreated PCL cannot harbor cells on its surface effectively. It is revealed that electrospun nanofibers can overcome this shortcoming and are promising candidates for tissue-engineered vascular scaffolds ${ }^{26}$. Synthesized vascular endothelial growth factor (VEGF) nanoparticles were loaded into PCL solution for electrospinning to make stem cells differentiate into endothelial cells successfully ${ }^{27}$. Jirofti et al. ${ }^{28}$ introduced a co-electrospinning method to fabricate compliant small-diameter vascular scaffolds using composite polyethylene terephthalate and elastic polytetrafluoroethylene (PCL/PU). Mechanical properties were significantly improved by this applied method and scaffolds could meet clinical requirements. In various studies, different types of electrospun vascular tubes have been manufactured and used to promote cell affinity and activity on fiber surfaces. Fiber topography affects the morphological and biochemical changes of the endothelial cell by directing cell migration and spread ${ }^{29}$. In our work, the tubular nanofibrous PCL membrane created by electrospinning was beneficial to proliferation and epithelization of endothelial cells. In addition, the fabricated tube exhibited the attractive properties of high strength and ductility. Tensile strain of the fabricated tube in the electrospun group was about ten times greater than in the control group.

Another important issue for small-diameter vascular scaffolds is suture retention strength 
(SRS). Creating scaffolds with sufficient SRS is key for successful surgical anastomosis ${ }^{30}$. Vascular grafts fabricated by composite material with flexible polylactic acid (PLA) and PCL have better SRS compared to single-material constructs ${ }^{31}$. Alex et al. ${ }^{22}$ used hexafluoroisopropanol (HFIP) as solvent to dissolve silk fibroin for improved mechanical properties of the electrospun structure. The burst pressure and suture retention were $1441 \pm$ $41 \mathrm{mmHg}$ and close to $1 \mathrm{~N}$, respectively. In our study, the suture retention of the tubular structure reached $2.192 \pm 0.176 \mathrm{~N}$, much larger than that of the common carotid artery $(0.235$ $\pm 0.026 \mathrm{~N})$, indicating its feasibility for clinical application.

3D bioprinting is an advanced technology that combines different cells with biocompatible materials ${ }^{32,33}$. Due to the limitation of mechanical properties in natural materials, most bioprinting research has concentrated on endothelialization of a vascular inner layer or in vitro study of vascular models ${ }^{34}$. In particular, various 3D bioprinted microvascular networks have been developed to provide oxygen and nutrition for tissue-engineered tissues and organs ${ }^{35}$. Recently, Lei et al. ${ }^{24}$ fabricated a bilayered bionic vascular vessel in a single step using 3D bioprinting technology by adjusting the concentration of GelMA-based bioink for the inner and external layers. HUVECs and SMCs were successfully stratified in the printing process ${ }^{24}$. In the present study, with the advantages of high precision and uniform ink deposition 3D bioprinting, we used GelMA-based SMCs to create an external membrane on which cells were homogenously located to form the external layer of small diameter vessel-like scaffolds. Freeman et al. [37] used gelatin-fibrinogen blended bioink and a specifically modified rotary printer to creat a bionic blood vessel with a monolayer of endothelial cells. Burst pressure of this bionic vessel 
can reach $1110 \mathrm{mmHg}$, which is $52 \%$ that of the saphenous vein ${ }^{36}$. We improved the rotary printing method by loading a clockwise motor and a counterclockwise motor at each end of the circular mandrel to ensure stability during the bioprinting.

Single technology cannot simulate the complex biological and mechanical properties of natural blood vessels. By combining thermally-induced phase separation (TIPS) with electrospinning, David et al. ${ }^{37}$ fabricated an elastomeric bilayered tubular structure that maintains higher patency after the implantation as aortic interposition grafts. In this study, we combined electrospinning with rotary bioprinting and manufactured bionic vascular vessel structures with mechanical properties comparable to, or better than, native blood vessels. These vascular vessel structures also display biological properties. The inner layer of PCL nanofibers modified by electrospinning mimics the natural extracellular matrix, which allows adhesion and functionalization of endothelial cells. The bioprinted GelMA-based porous outer layer scaffold enables smooth muscle cells to aggregate, migrate and secrete large amounts of collagen to form elastic muscle tissue. The method integrates the advantages of two technologies to produce a new way to fabricate small-diameter bionic vessels for clinical application.

\section{Conclusion}

In this study, we successfully constructed artificial vessel grafts using a new method. We modified PCL by electrospinning, bioprinted with GelMA-based bioink containing SMCs, and perfused HUVECs to fabricate a small-diameter bionic vessel containing smooth muscle cells and endothelial cells. Combining the advantages of these two technologies, the artificial graft showed good elasticity, burst resistance and suture retention. Perfused HUVECs and 
bioprinted SMCs maintained good activity and function in the structure after culture. This approach may fill the need for the clinical transformation of tissue-engineered blood vessels. In addition, this method is suitable for other tubular tissue structures, such as urethra, trachea, and intestine. It could provide a new method for constructing artificial bionic tissue with both mechanical strength and biological activity.

\section{Methods}

\section{Material}

All chemical reagents were purchased from the Sigma-Aldrich company unless otherwise specified. Cells used in the experiment were from generations 4 to 8 .

\section{Synthesis of GelMA}

The GelMA was synthesized by a chemical reaction ${ }^{24} ; 8.0$ g gelatin (type A; 300 bloom from porcine skin) was dissolved in $50 \mathrm{ml} 0.25 \mathrm{M}$ carbonate-bicarbonate buffer ( $\mathrm{pH}$ 9.2) for $1 \mathrm{~h}$ at $60{ }^{\circ} \mathrm{C}$. Then, $0.8 \mathrm{ml}$ methacrylic anhydride (MA) was slowly added to the solution while stirring and allowed to react for $3 \mathrm{~h}$ at $55^{\circ} \mathrm{C}$. The reaction was terminated with $80 \mathrm{ml}$ Dulbecco's phosphate buffered saline (DPBS) and the mixture dialyzed with 12-14 kDa cut-off dialytic tubes at $37^{\circ} \mathrm{C}$ for 7 days. The dialyzed solution was freeze-dried and stored at $-20^{\circ} \mathrm{C}$ until use.

\section{Analysis of ${ }^{1} \mathbf{H}-\mathbf{N M R}$}

The synthesis of GelMA was examined through ${ }^{1} \mathrm{H}-\mathrm{NMR}$. GelMA polymer was dissolved $(30 \mathrm{mg} / \mathrm{ml})$ in deuterium oxide $\left(\mathrm{D}_{2} \mathrm{O}\right)$ at $55^{\circ} \mathrm{C}$ and an NMR spectrometer $\left({ }^{1} \mathrm{H}-\mathrm{NMR}\right.$, Bruker, Billerica, MA) with a single axis gradient at $400 \mathrm{MHz}$ used to get the spectra. Gelatin 
was tested as control.

\section{Determination of methacrylation degree by TNBS}

The methacrylation degree of GelMA was measured by 2,4,6-trinitrobenzenesulfonic acid (TNBS) ${ }^{38}$. A $200 \mu \mathrm{g} / \mathrm{ml}$ mixture was obtained by dissolving GelMA into 0.1 M sodium bicarbonate solution at $37^{\circ} \mathrm{C}$ for $1 \mathrm{~h}$. Next, $250 \mu \mathrm{TNBS}$ was added and allowed to react at $37^{\circ} \mathrm{C}$ for $2 \mathrm{~h}$. To terminate the reaction, $250 \mu \mathrm{L} 10 \%$ sodium dodecyl sulfate (SDS) and 125 $\mu \mathrm{L} 1 \mathrm{~N}$ hydrochloric acid (HCl) were added. Optical density (OD) was obtained by microplate reader (SpectraMax M5, Molecular, USA) at $335 \mathrm{~mm}$. Gelatin was used as a control. Methacrylation degree was calculated as:

Methacrylation degree $(\%)=(1-$ OD of GelMA/OD of Gelatin $) \times 100(\%)$

\section{Electrospinning}

The electrospinning device consisted of a rotating and translating circular mandrel to ensure uniform deposition of nanofibers. Electrospun nanofiber tubes were fabricated using poly(ع-caprolactone) (Mw. 43000-50000; Polyscience Inc). Pluronic solution was ejected through an 18-gauge needle at a flow rate of $1 \mathrm{ml} / \mathrm{h}$. Under a voltage of $25 \mathrm{kV}$ and using a rotation rate of $1000 \mathrm{rpm}$, Pluronic fiber film was fabricated on a $1.55 \mathrm{~mm}$ circular mandrel at a distance of $15 \mathrm{~cm}$ from the needle to facilitate the removal of the PCL tube. This generated an electrospun tube with a $1.62 \mathrm{~mm}$ inner diameter and $0.31 \mathrm{~mm}$ thick walls. The tube washed three times with sterile PBS, disinfected in 70\% ethanol, air dried, and then exposed to ultraviolet light for 30 minutes. The tubes were kept in the fume hood until use.

\section{Preparation of different concentrations GelMA solution samples}

Different concentrations GelMA-based solutions were prepared with GelMA, gelatin 
(type A; 80 bloom from porcine skin), glycerol, HA and a photo-crosslinking agent (irgacure $2959)$ to increase printability. Briefly, $20 \mathrm{mg} / \mathrm{ml} \mathrm{(2 \% ),} 50 \mathrm{mg} / \mathrm{ml}(5 \%)$ or $80 \mathrm{mg} / \mathrm{ml}(8 \%)$ GelMA was mixed in DPBS with $30 \mathrm{mg} / \mathrm{ml}$ gelatin, $3 \mathrm{mg} / \mathrm{ml} \mathrm{HA,} \mathrm{10 \%} \mathrm{(v/v)} \mathrm{glycerol} \mathrm{and} \mathrm{1 \%}$ (w/v) irgacure 2959 to create different concentrations of GelMA solution. Samples $1 \mathrm{~cm}$ in diameter and $2 \mathrm{~mm}$ thick were obtained in the mold by crosslinking for $100 \mathrm{~s}$ under ultraviolet (UV) light with $200 \mathrm{mV} / \mathrm{cm}^{2}$ strength and $365 \mathrm{~mm}$ wavelength.

\section{Scanning electron microscopy}

Electrospun PCL samples were coated with gold using a sputter coater (EM Ace600, Leica) and then observed under a scanning electron microscope (Flex SEM1000, Hitachi). Different concentrations of GelMA samples were put into DI water at $37^{\circ} \mathrm{C}$ for 2 days and then freeze-dried. A cross section of the structure was coated and observed as above. The diameters of PCL fiber and GelMA samples were analyzed in ImageJ.

\section{Rheological test}

The rheology of the GelMA-based solution of different concentrations was analyzed using an HR-2 Discovery Rheometer (TA instruments, Newcastle, DE). In brief, storage modulus $\left(\mathrm{G}^{\prime}\right)$ and loss modulus $\left(\mathrm{G}^{\prime \prime}\right)$ were measured using an $8 \mathrm{~mm}$ steel plate geometry at room temperature. Strain was measured from 0.01 to $3 \%$ at an oscillation frequency of $1 \mathrm{rad} / \mathrm{s}$. Frequency was measured from 1 to $100 \mathrm{~Hz}$ with a $1 \%$ constant strain.

\section{Bioprinting of bionic blood vessel grafts}

The self-designed rotary bioprinter was combined with the Bio-X 3D bioprinter (Celink, Gothenburg, Sweden) and clockwise and counterclockwise rotating dual motors. The Bio-X 3D bioprinter had a XYZ stage controller, a distributing module and a chamber. It could 
realize multi-material and multi-temperature controlled bioprinting. Combined with the specially designed dual motors, the movement of the XYZ axes and rotation of the central axis could be carried out simultaneously. The dual motors were controlled by the same control board to rotate at the same speed and maintain the balance of the circular mandrel.

For printing the acellular tubular structure, the 5\% GelMA-based solution was added into the syringe with $300 \mu \mathrm{m}$ nozzle (Izumi, Japan). The printing was carried out on the outer layer of electrospun PCL tube with $100 \mathrm{kPa}$ print pressure, $5 \mathrm{~mm} / \mathrm{min}$ speed and $40 \mathrm{rpm}$ rotation speed at $20^{\circ} \mathrm{C}$. After printing one layer along the straight line, the nozzle returned to the starting point, and raised the $\mathrm{z}$-axis by $0.4 \mathrm{~mm}$ before printing again. A $0.78 \mathrm{~mm}$ thick outer layer of GelMA was formed and the acellular structure removed from the circular mandrel.

For construction of bionic vascular vessel, $10 \times 10^{6}$ cells $/ \mathrm{ml}$ SMCs were evenly mixed into 5\% GelMA solution by slow blowing, and then printed as previously described. A cell suspension of $30 \times 10^{6}$ cells/ml HUVECs was injected into the channel and the structure rotated $90^{\circ}$ every $30 \mathrm{~min}$. HUVECs were given $2 \mathrm{~h}$ in a $37^{\circ} \mathrm{C}$ incubator for adhesion and then non-adherent cells were washed away with DPBS to ensure patency of the lumen (Figure 1).

\section{Mechanical tests}

\section{Tensile test}

Electrospun PCL tubes were cut into strips and an Instron mechanical tester (model 5533, Instron Corporation, Norwood, Ma) used to test the tensile force using the maximum load of $10 \mathrm{~N}$. At a speed of $0.2 \mathrm{~mm} / \mathrm{s}$, the samples were stretched slowly until tearing occurred. The same thickness of PCL samples without the electrospinning treatment were used as the 
control.

\section{Burst pressure test}

Acellular tubular structures fabricated through combined electrospinning and rotary printing were directly connected to a pressure tube through a conical adapter. Normal saline was slowly and continuously pumped from a $50 \mathrm{ml}$ syringe into the graft and the pressure measured with a pressure transducer. The pressure measured just before rupture of the graft was taken as burst pressure. Carotid arteries of the rabbit were used as control.

\section{Suture pull-out test}

The suture pull-out test was used to test SRS. Both ends of the acellular tubular structures were threaded with a 5-0 suture and fixed on the Instron tensile machine. Suture retention test was performed at a constant pull-out rate of $2 \mathrm{~mm} / \mathrm{min}$ and the force tested under a $50 \mathrm{~N}$ load cell. The data were expressed as the structure being split. Carotid arteries of the rabbit were used as control.

\section{Cell culture}

HUVECs and SMCs, purchased from Lonza, were cultured in EGM-2 (Lonza) and smooth muscle cell growth medium 2 (Promocell), respectively. Antibody (1\% v/v penicillin and streptomycin) was added to the medium. EGM-2 and smooth muscle cell growth medium were mixed with the ratio of $1: 1$ to culture the bionic vascular tissue. All cell cultures were maintained in $5 \% \mathrm{CO}_{2}$ and $95 \%$ relative humidity at $37^{\circ} \mathrm{C}$ and medium was changed every 2 days. 


\section{In vitro biological evaluation of cell viability and proliferation}

Cell viability was detected using the live/dead viability/cytotoxicity kit (Invitrogen). GelMA bioink containing $10 \times 10^{6}$ cells/ml SMCs was bioprinted into 24 -well plates and 30 $\times 10^{6}$ cells/ml HUVECs suspension was seed onto the electrospun PCL fibers as previously described. After being in cultured for 1, 4 and 7 days, the tissues were washed by DPBS three times and incubated with $0.5 \mu \mathrm{L} / \mathrm{ml}$ Calcein $\mathrm{AM}$ and $2 \mu \mathrm{L} / \mathrm{ml}$ ethidium homodimer for 45 min at $37^{\circ} \mathrm{C}$. Images were observed under a fluorescence microscope (Zeiss Axiovert 200M, Oberkochen). Six random fields were used to analyze viability with ImageJ.

Cell proliferation was assessed using a CCK-8 kit. Samples were washed with DPBS three times before $900 \mu \mathrm{L}$ medium and $100 \mu \mathrm{L}$ CCK- 8 solution added. Optical density was read with a SpectraMax M5 at $460 \mathrm{~nm}$ after incubating at $37^{\circ} \mathrm{C}$ for $3 \mathrm{~h}$.

\section{SEM of bionic vascular vessel}

Bionic tissue samples were fixed with $2.5 \%$ glutaraldehyde at $4{ }^{\circ} \mathrm{C}$ for $4 \mathrm{~h}$ and then gradient dehydrated with $30 \%, 50 \%, 70 \%, 80 \%, 90 \%, 95 \%$, and $100 \%$ ethanol, before being placed into a critical point dryer (Leica, EM CPD 300, Germany) to replace ethanol by $\mathrm{CO}_{2}$. The samples were coated with gold and the microstructure of the cells at different culture stages observed by SEM.

\section{Histological and immunofluorescence analysis}

Bionic grafts were embedded with optimal cutting temperature compound and the samples cut into $15 \mu \mathrm{m}$ section in a cryostat at $-20^{\circ} \mathrm{C}$. Histology and collagen secretion were observed by Masson staining.

Bionic vascular tissue samples were characterized by immunofluorescence staining with 
specific antibodies. HUVECs were labeled with the primary antibody of mouse anti-human CD31 (1:50, Abcam) and a secondary antibody of Alexa Fluor 488 goat anti-mouse (1:500, Abcam) to detect lumen formation. SMCs were labeled with the primary antibody of rabbit anti-human $\alpha$-SMA (1:200, Abcam) and a secondary antibody of Alexa Fluor 594 Donkey anti-rabbit (1:500, Abcam). All sections were counterstained with DAPI, and fluorescence images were acquired using a fluorescent microscope.

\title{
Statistical analysis
}

All data are expressed as means $\pm \mathrm{SD}$ (standard deviation) and differences analyzed with Student's t-tests; $P<0.05$ was considered statistically significant.

\begin{abstract}
Abbreviations
PCL: poly(e-caprolactone); 3D: three-dimensional; CVDs: Cardiovascular diseases; SDBVs: small-diameter blood vessels; SMCs: smooth muscle cells; HUVECs: human umbilical vein endothelial cells; GelMA: methacrylated gelatin; SRS: suture retention strength.
\end{abstract}

\section{Acknowledgements}

The authors thanks Jean for the language modification.

\section{Authors' contributions}

HRX, WWZ, JJH designed the experiments. QHJ and GLZ performed the experiments. FY drafted and wrote the manuscript. LX improved the bioprinter. GZJ and TLF made the interpretation of data. All authors read and approved the final manuscript.

\section{Funding}

This work was supported by the National Natural Science Foundation of China (31900969), 
Suzhou Municipal Science and Technology Bureau (SYS2020071), Suzhou Science and Education for Healthy (KJXW2019073) and the Gusu Health Talent Training Project of Suzhou (GSWS2019088).

\section{Availability of data and materials}

All date generated and analyzed during this study are published in this manuscript.

\section{Ethics approval and consent to participate}

The study was approved by the Ethics Committee of Soochow University of Medicine and Committee of the Experimental Animal Center of Soochow University.

\section{Consent for publication}

Not applicable

\section{Competing interests}

The authors declare that they have no competing interests.

\section{Author details}

${ }^{1}$ Institute of Hand Surgery, Ruihua Hospital Affiliated to Soochow University, 5 Tayun Road, Suzhou, Jiangsu 215100, China. ${ }^{2}$ Medicine of Soochow University, 199 Renai Road, Suzhou, Jiangsu 215000, China. ${ }^{3}$ Wake Forest Institute for Regenerative Medicine, Wake Forest University School of Medicine, 391 technology way, Winston Salem, NC 27101, USA. ${ }^{4}$ Department of Human Anatomy, Histology and Embryology, School of Biology and Basic Medical Sciences, Soochow University, 199 Renai Road, Suzhou, Jiangsu 215100, China

\section{References}

1. Zhang F, Xie Y, Celik H, Akkus O, Bernacki SH, King MW. Engineering small-caliber vascular grafts from collagen filaments and nanofibers with comparable mechanical properties to native vessels. Biofabrication. 2019;11(3):035020. http://doi.org/10.1088/1758-5090/ab15ce.

2. Zoghbi WA, Duncan T, Antman E, Barbosa M, Champagne B, Chen D, et al. Sustainable development goals and the future of cardiovascular health: a statement from the Global Cardiovascular Disease Taskforce. Glob Heart. 2014;9(3):273-274. http://doi.org/10.1161/JAHA.114.000504.

3. Eilenberg M, Enayati M, Ehebruster D, Grasl C, Walter I, Messner B, Baudis S, et al. Long Term 
Evaluation of Nanofibrous, Bioabsorbable Polycarbonate Urethane Grafts for Small Diameter Vessel Replacement in Rodents. European Journal of Vascular and Endovascular Surgery. 2020;59(4):643-652. http://doi.org/10.1016/j.ejvs.2019.11.004.

4. Pashneh-Tala S, MacNeil S, Claeyssens F. The Tissue-Engineered Vascular Graft-Past, Present, and Future. Tissue Engineering Part B-Reviews. 2016;22(1):68-100. http://doi.org/10.1089/ten.teb.2015.0100.

5. L'Heureux N, Dusserre N, Marini A, Garrido S, de la Fuente L, McAllister T. Technology Insight: the evolution of tissue-engineered vascular grafts - from research to clinical practice. Nature Clinical Practice Cardiovascular Medicine. 2007;4(7):389-395. http://doi.org/10.1038/ncpcardio0930.

6. Jang SR, Kim JI, Park CH, Kim CS. Development of Y-shaped small diameter artificial blood vessel with controlled topography via a modified electrospinning method. Materials Letters. 2020;264. http://doi.org/10.1016/j.matlet.2019.127113.

7. Yamanaka H, Yamaoka T, Mahara A, Morimoto N, Suzuki S. Tissue-engineered submillimeter-diameter vascular grafts for free flap survival in rat model. Biomaterials. 2018;179:156-163. http://doi.org/10.1016/j.biomaterials.2018.06.022.

8. Hibino N, Mejias D, Pietris N, Dean E, Yi T, Best C, et al. The innate immune system contributes to tissue-engineered vascular graft performance. FASEB J. 2015;29(6):2431-2438. http://doi.org/10.1096/fj.14-268334.

9. Zhang Y, Li XS, Guex AG, Liu SS, Muller E, Malini RI, et al, Rottmar M, Maniura-Weber K, Rossi RM, Spano F. A compliant and biomimetic three-layered vascular graft for small blood vessels. Biofabrication. 2017;9(2):025010. http://doi.org/10.1088/1758-5090/aa6bae.

10. Isenberg $B C$, Williams $C$, Tranquillo RT. Small-diameter artificial arteries engineered in vitro. Circ Res. 2006;98(1):25-35. http://doi.org/10.1161/01.RES.0000196867.12470.84.

11. Zhang YS, Oklu R, Dokmeci MR, Khademhosseini A. Three-Dimensional Bioprinting Strategies for Tissue Engineering. Cold Spring Harbor Perspectives in Medicine. 2018;8(2). http://doi.org/10.1101/cshperspect.a025718.

12. Murphy SV, Atala A. 3D bioprinting of tissues and organs. Nat Biotechnol. 2014;32(8):773-785. http://doi.org/10.1038/nbt.2958.

13. Kolesky DB, Homan KA, Skylar-Scott MA, Lewis JA. Three-dimensional bioprinting of thick vascularized tissues. Proc Natl Acad Sci U S A. 2016;113(12):3179-3184. http://doi.org/10.1073/pnas.1521342113.

14. Cui H, Zhu W, Huang Y, Liu C, Yu ZX, Nowicki M, et al. In vitro and in vivo evaluation of 3D bioprinted small-diameter vasculature with smooth muscle and endothelium. Biofabrication. 2019;12(1):015004. http://doi.org/10.1088/1758-5090/ab402c.

15. Cui H, Nowicki M, Fisher JP, Zhang LG. 3D Bioprinting for Organ Regeneration. Adv Healthc Mater. 2017;6(1). http://doi.org/10.1002/adhm.201601118.

16. Ji S, Almeida E, Guvendiren M. 3D bioprinting of complex channels within cell-laden hydrogels. Acta Biomaterialia. 2019;95:214-224. http://doi.org/10.1016/j.actbio.2019.02.038.

17. Yang Y, Lei D, Zou H, Huang S, Yang Q, Li S, et al. Hybrid electrospun rapamycin-loaded small-diameter decellularized vascular grafts effectively inhibit intimal hyperplasia. Acta Biomater. 2019;97:321-332. http://doi.org/10.1016/j.actbio.2019.06.037.

18. Stefani I, Cooper-White JJ. Development of an in-process UV-crosslinked, electrospun PCL/aPLA-co-TMC composite polymer for tubular tissue engineering applications. Acta Biomater. 2016;36:231-240. http://doi.org/10.1016/j.actbio.2016.03.013. 
19. Holland I, Logan J, Shi J, McCormick C, Liu D, Shu W. 3D biofabrication for tubular tissue engineering. Biodes Manuf. 2018;1(2):89-100. http://doi.org/10.1007/s42242-018-0013-2.

20. Rafique M, Wei T, Sun Q, Midgley AC, Huang Z, Wang T, et al. The effect of hypoxia-mimicking responses on improving the regeneration of artificial vascular grafts. Biomaterials. 2021;271:120746. http://doi.org/10.1016/j.biomaterials.2021.120746.

21. Ashraf R, Sofi HS, Malik A, Beigh MA, Hamid R, Sheikh FA. Recent Trends in the Fabrication of Starch Nanofibers: Electrospinning and Non-electrospinning Routes and Their Applications in Biotechnology. Applied Biochemistry and Biotechnology. 2019;187(1):47-74. http://doi.org/10.1007/s12010-018-2797-0.

22. Chan AHP, Filipe EC, Tan RP, Santos M, Yang N, Hung J, et al. Altered processing enhances the efficacy of small-diameter silk fibroin vascular grafts. Sci Rep. 2019;9(1):17461. http://doi.org/10.1038/s41598-019-53972-y.

23. Wang D, Xu Y, Li Q, Turng LS. Artificial small-diameter blood vessels: materials, fabrication, surface modification, mechanical properties, and bioactive functionalities. J Mater Chem B.

2020;8(9):1801-1822. http://doi.org/10.1039/c9tb01849b.

24. Xu L, Varkey M, Jorgensen A, Ju J, Jin Q, Park JH, et al. Bioprinting small diameter blood vessel constructs with an endothelial and smooth muscle cell bilayer in a single step. Biofabrication. 2020;12(4):045012. http://doi.org/10.1088/1758-5090/aba2b6.

25. de Valence S, Tille JC, Mugnai D, Mrowczynski W, Gurny R, Moller M, et al. Long term performance of polycaprolactone vascular grafts in a rat abdominal aorta replacement model. Biomaterials. 2012;33(1):38-47. http://doi.org/10.1016/j.biomaterials.2011.09.024.

26. Swetha S, Lavanya K, Sruthi R, Selvamurugan N. An insight into cell-laden 3D-printed constructs for bone tissue engineering. Journal of Materials Chemistry B. 2020;8(43):9836-9862. http://doi.org/10.1039/d0tb02019b.

27. Jiang YC, Wang XF, Xu YY, Qiao YH, Guo X, Wang DF, et al. Polycaprolactone Nanofibers Containing Vascular Endothelial Growth Factor-Encapsulated Gelatin Particles Enhance Mesenchymal Stem Cell Differentiation and Angiogenesis of Endothelial Cells. Biomacromolecules. 2018;19(9):3747-3753. http://doi.org/10.1021/acs.biomac.8b00870.

28. Jirofti N, Mohebbi-Kalhori D, Samimi A, Hadjizadeh A, Kazemzadeh GH. Small-diameter vascular graft using co-electrospun composite PCL/PU nanofibers. Biomedical Materials. 2018;13(5). http://doi.org/10.1088/1748-605X/aad4b5.

29. Gluais M, Clouet J, Fusellier M, Decante C, Moraru C, Dutilleul M, et al. In vitro and in vivo evaluation of an electrospun-aligned microfibrous implant for Annulus fibrosus repair. Biomaterials. 2019;205:81-93. http://doi.org/10.1016/j.joca.2019.02.452.

30. Chaparro FJ, Matusicky ME, Allen MJ, Lannutti JJ. Biomimetic microstructural reorganization during suture retention strength evaluation of electrospun vascular scaffolds. J Biomed Mater Res B Appl Biomater. 2016;104(8):1525-1534. http://doi.org/10.1002/jbm.b.33493.

31. Li C, Wang F, Douglas G, Zhang Z, Guidoin R, Wang L. Comprehensive mechanical characterization of PLA fabric combined with PCL to form a composite structure vascular graft. J Mech Behav Biomed Mater. 2017;69:39-49. http://doi.org/10.1016/j.jmbbm.2016.11.005.

32. Hong H, Seo YB, Kim DY, Lee JS, Lee YJ, Lee H, et al. Digital light processing 3D printed silk fibroin hydrogel for cartilage tissue engineering. Biomaterials. 2020;232:119679. http://doi.org/10.1016/j.biomaterials.2019.119679.

33. Tomasina C, Bodet T, Mota C, Moroni L, Camarero-Espinosa S. Bioprinting Vasculature: Materials, 
Cells and Emergent Techniques. Materials (Basel). 2019;12(17). http://doi.org/10.3390/ma12172701.

34. Miller JS, Stevens KR, Yang MT, Baker BM, Nguyen D-HT, Cohen DM, et al. Rapid casting of patterned vascular networks for perfusable engineered three-dimensional tissues. Nature Materials. 2012;11(9):768-774. http://doi.org/10.1038/NMAT3357.

35. Zhang G, Varkey M, Wang Z, Xie B, Hou R, Atala A. ECM concentration and cell-mediated traction forces play a role in vascular network assembly in 3D bioprinted tissue. Biotechnol Bioeng. 2020;117(4):1148-1158. http://doi.org/10.1002/bit.27250.

36. Freeman S, Ramos R, Alexis Chando P, Zhou L, Reeser K, Jin S, et al. A bioink blend for rotary 3D bioprinting tissue engineered small-diameter vascular constructs. Acta Biomater. 2019;95:152-164. http://doi.org/10.1016/j.actbio.2019.06.052.

37. He W, Nieponice A, Soletti L, Hong Y, Gharaibeh B, Crisan M, Usas A, et al. Pericyte-based human tissue engineered vascular grafts. Biomaterials. 2010;31(32):8235-8244. http://doi.org/10.1016/j.biomaterials.2010.07.034.

38. Ali M, Pr AK, Yoo JJ, Zahran F, Atala A, Lee SJ. A Photo-Crosslinkable Kidney ECM-Derived Bioink Accelerates Renal Tissue Formation. Adv Healthc Mater. 2019;8(7):e1800992. http://doi.org/10.1002/adhm.201800992. 


\section{Figure Legends}

\section{Figure 1}

Schematic showing the novel approach for fabricating small-diameter bionic vascular tissue by combining nanofiber electrospinning and rotary bioprinting.

\section{Figure 2}

The analysis of electrospun PCL and different concentration of GelMA solutions (a) Photo image of electrospun PCL. (b) SEM of electrospun PCL. (c) Tensile stress assessment of electrospun PCL and PCL without electrospinning treatment $(* * *, P<0.001, \mathrm{n}=6)$. (d) Photo image of different concentration GelMA. (e) SEM of different concentration GelMA. (f) Pore size assessment of different concentration GelMA (***, $P<0.001)$. (g, h) Dynamic mechanical analysis of different concentration GelMA solution. Storage modulus $\left(\mathrm{G}^{\prime}\right)$ and loss modulus $\left(\mathrm{G}^{\prime \prime}\right)$ were measured with the changes of angular frequency and stain $(n=6)$.

\section{Figure 3}

Analysis of acellular tubular structure. (a) Phone image of acellular tubular structure. (b) Structure completely restored after the applied pressure removed; (i) pressure applied (ii) pressure removed. (c) SEM of acellular tubular structure; (i) inner (ii) junction (iii) GelMA. (d) Maximal burst pressure before failure (***, $P<0.001, \mathrm{n}=6$ ). (e) Maximal cutting force before failure $(*, P<0.05, \mathrm{n}=6)$.

\section{Figure 4}

Viability, proliferation and microstructure of HUVECs on the surface of nanofiber electrospun PCL. (a) Live/dead stain of HUVECs on days 1, 4, and 7. (b) Cell viability of HUVECs. Cell survival rate of all groups was $>85 \%$. (c) Cell proliferation by CCK- 8 assay $(* * *, P<0.001$; NS, not significant, $\mathrm{n}=4)$. (d) Microstructure changes of HUVECs on fiber observed by SEM. 


\section{Figure 5}

Viability, proliferation and microstructure of SMCs in GelMA after bioprinting. (a) Live/dead stain of SMCs (Day 1, Day 4, Day 7). (b) Cell viability of SMCs. (Cell survival rate of all groups was more than 90\%) (c) Cell proliferation by CCK-8 assay $\left(^{*}, P<0.05\right.$; **, $P<0.01$; NS, not significant, $n=4$ ). (d) Microstructure of SMCs in GelMA observed by SEM after seven days of cultivation.

\section{Figure 6}

Masson and immunofluorescence staining of bionic vascular tissue. (a) Masson staining: (i) SMCs in GelMA, (ii) Junction, (iii) HUVECs on the surface of fiber. (b) Immunofluorescence of bionic vascular. (CD31, green; $\alpha$-sma, red; DAPI, blue). (c) Immunofluorescence staining in different positions of bionic vascular tissue: (i) Outer, (ii) GelMA, (iii) Junction, (iv) Inner.

\section{Supplementary Figure 1}

The ${ }^{1} \mathrm{H}-\mathrm{NMR}$ of GelMA and gelatin. Two characteristic peaks appeared at 5.5-6.0 ppm in GelMA. 


\section{Figures}

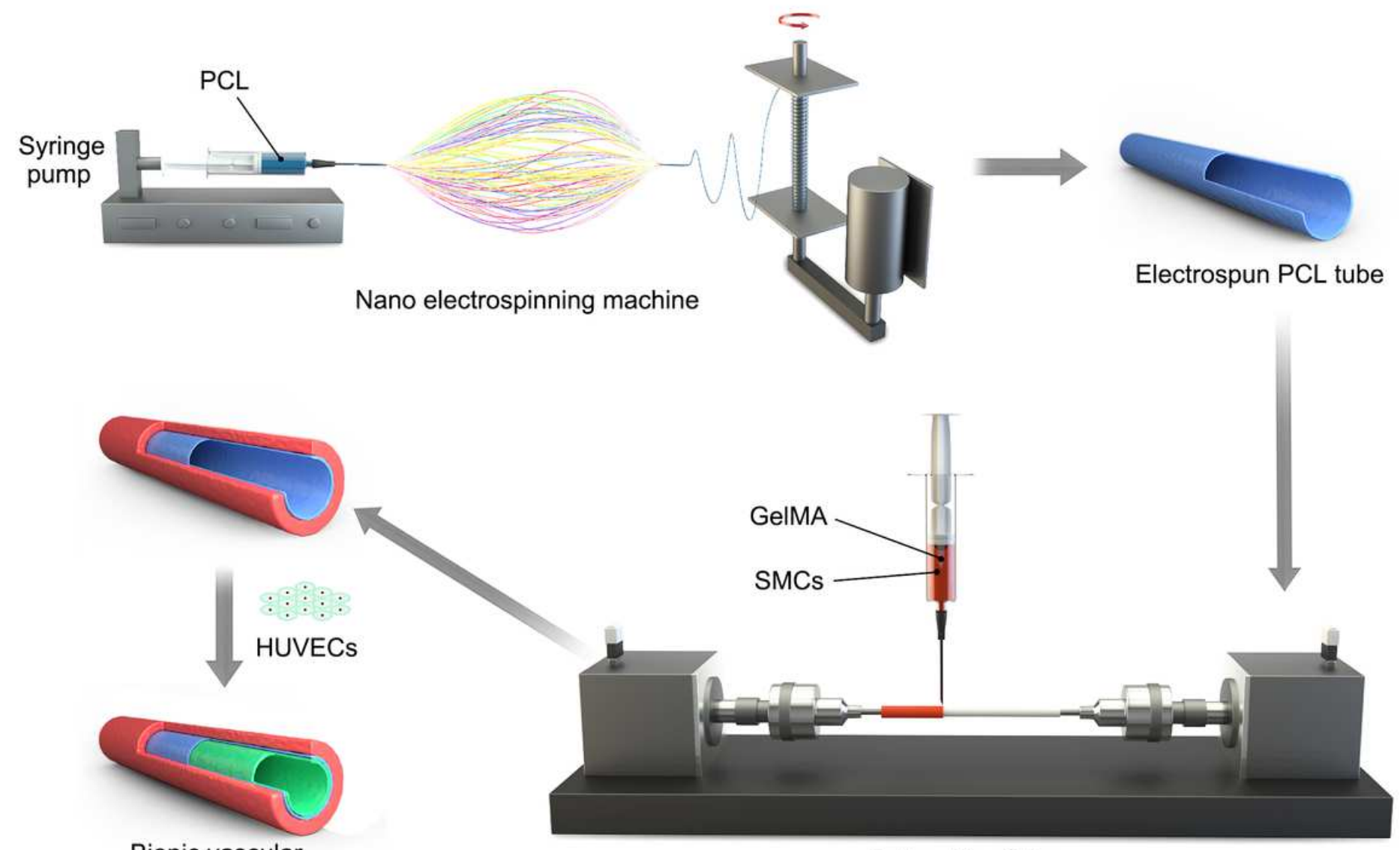

Bionic vascular

Rotary bioprinter

\section{Figure 1}

Schematic showing the novel approach for fabricating small-diameter bionic vascular tissue by combining nanofiber electrospinning and rotary bioprinting. 
a

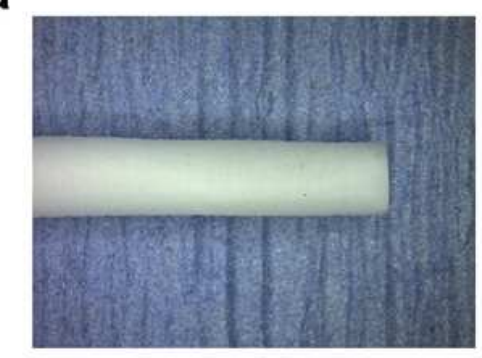

d

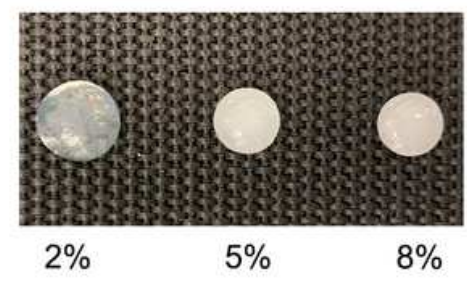

f

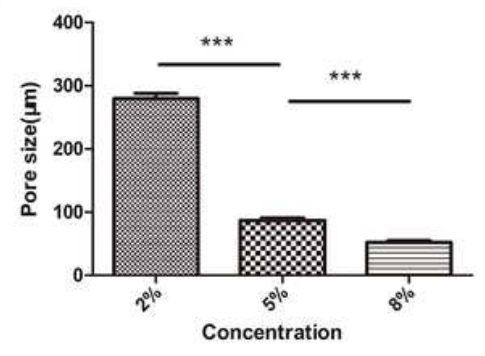

b
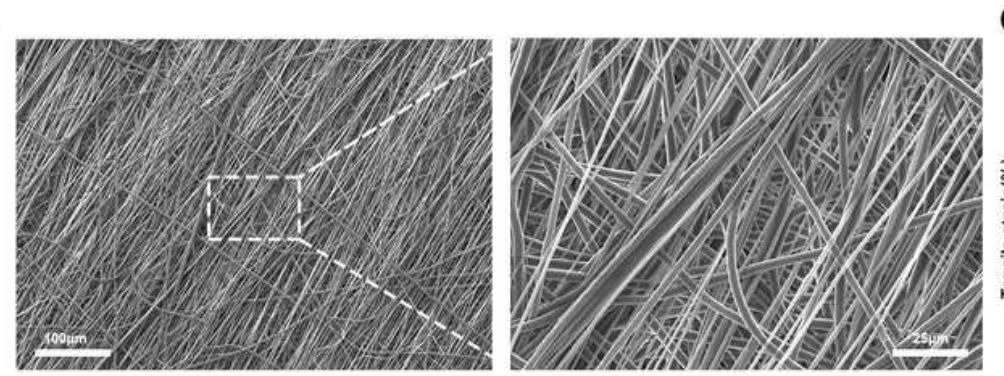

C

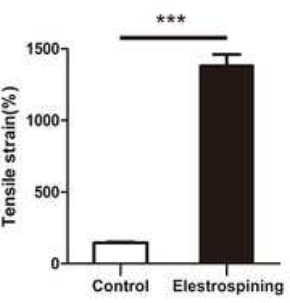

e
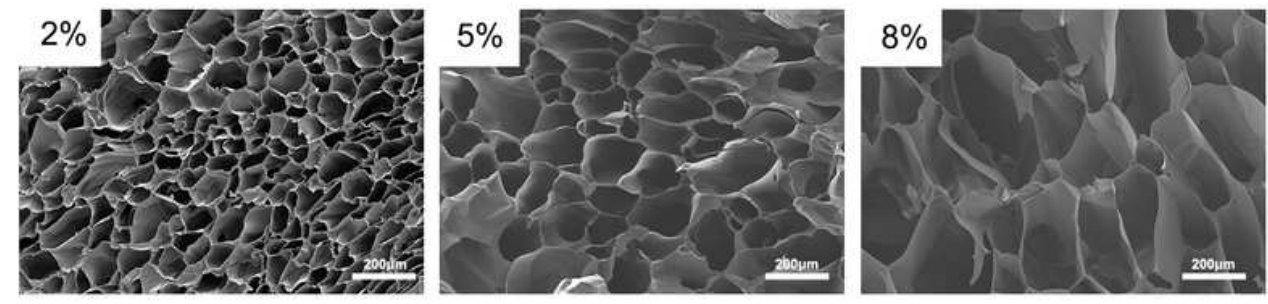

h

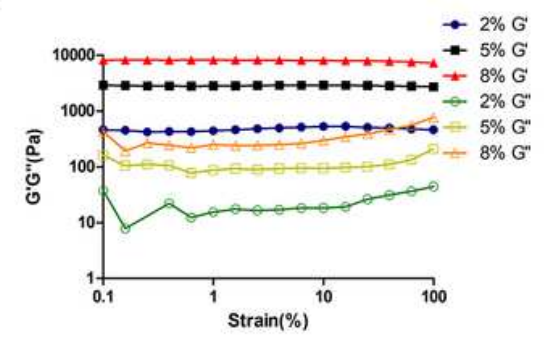

Figure 2

The analysis of electrospun PCL and different concentration of GelMA solutions (a) Photo image of electrospun PCL. (b) SEM of electrospun PCL. (c) Tensile stress assessment of electrospun PCL and PCL without electrospinning treatment $(* \star \star, P<0.001, n=6)$. (d) Photo image of different concentration GelMA. (e) SEM of different concentration GelMA. (f) Pore size assessment of different concentration

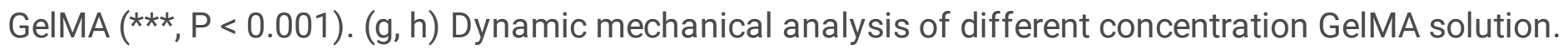
Storage modulus (GD) and loss modulus (GD) were measured with the changes of angular frequency and stain $(n=6)$.

a

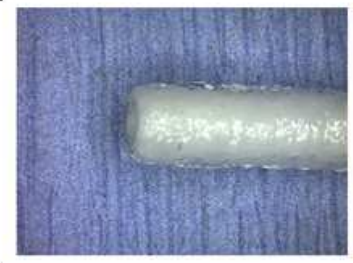

C

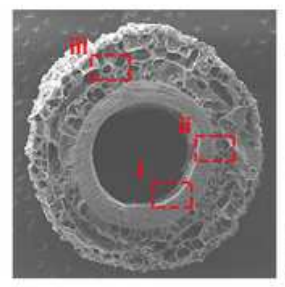

b
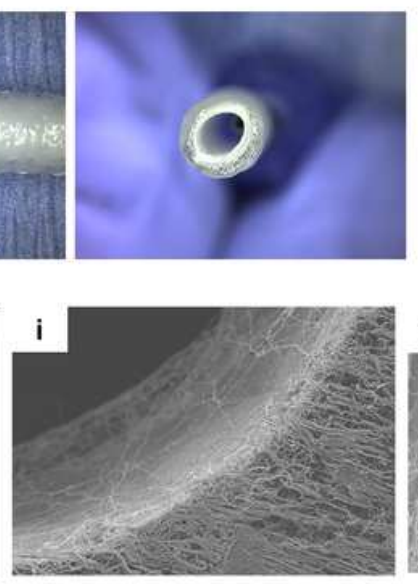
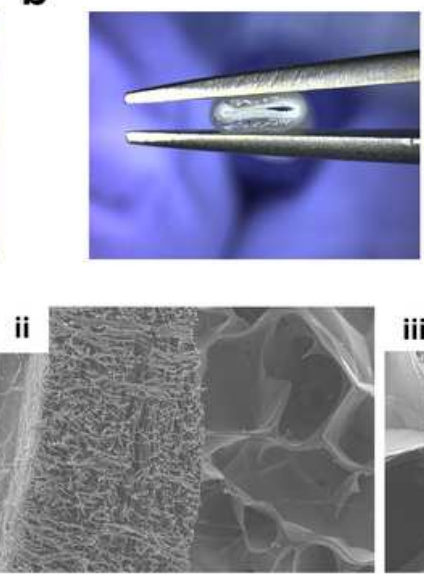
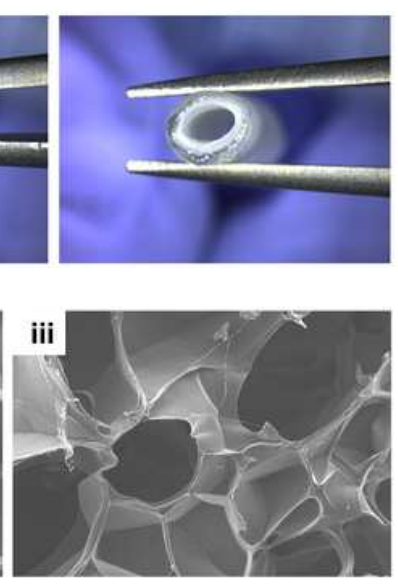

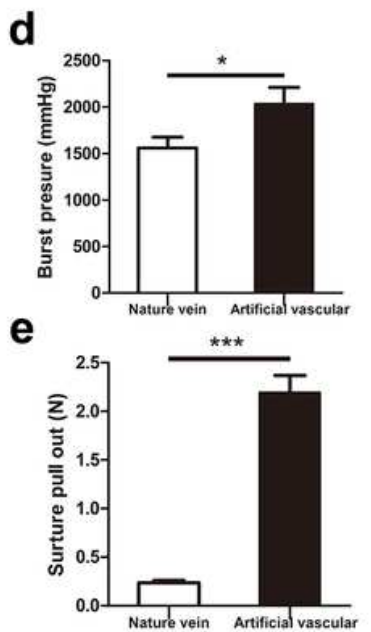




\section{Figure 3}

Analysis of acellular tubular structure. (a) Phone image of acellular tubular structure. (b) Structure completely restored after the applied pressure removed; (i) pressure applied (ii) pressure removed. (c) SEM of acellular tubular structure; (i) inner (ii) junction (iii) GelMA. (d) Maximal burst pressure before failure (***, $P<0.001, n=6)$. (e) Maximal cutting force before failure (*, $P<0.05, n=6$ ).

a
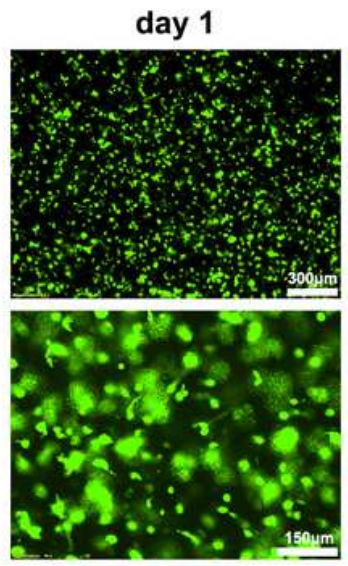

day 4
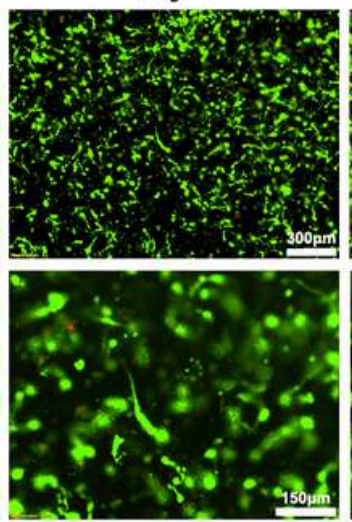

day 7

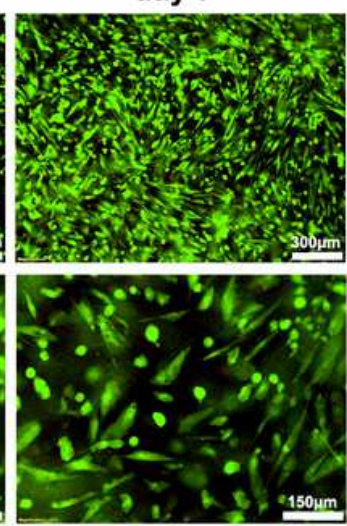

b
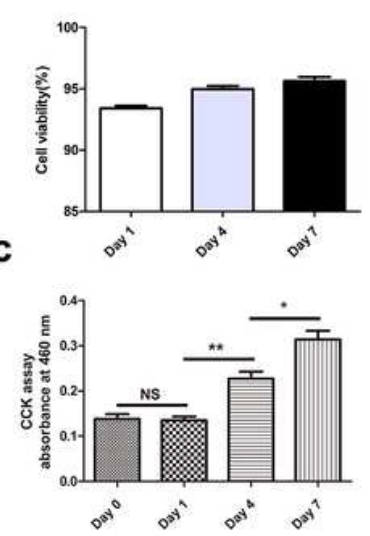

d
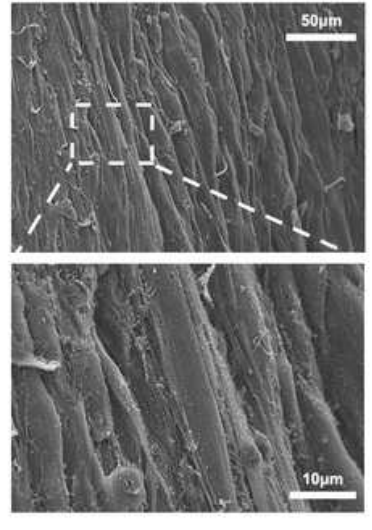

\section{Figure 4}

Viability, proliferation and microstructure of HUVECs on the surface of nanofiber electrospun PCL. (a) Live/dead stain of HUVECs on days 1, 4, and 7. (b) Cell viability of HUVECs. Cell survival rate of all groups was $>85 \%$. (c) Cell proliferation by CCK-8 assay ( $\star \star \star, ~ P<0.001$; NS, not significant, $n=4$ ). (d) Microstructure changes of HUVECs on fiber observed by SEM. 
a
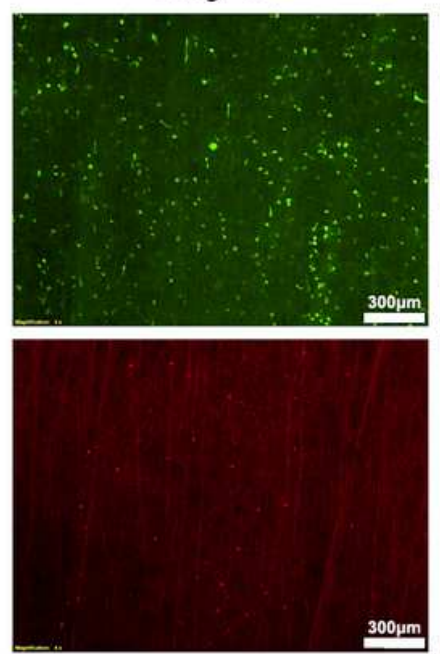

d

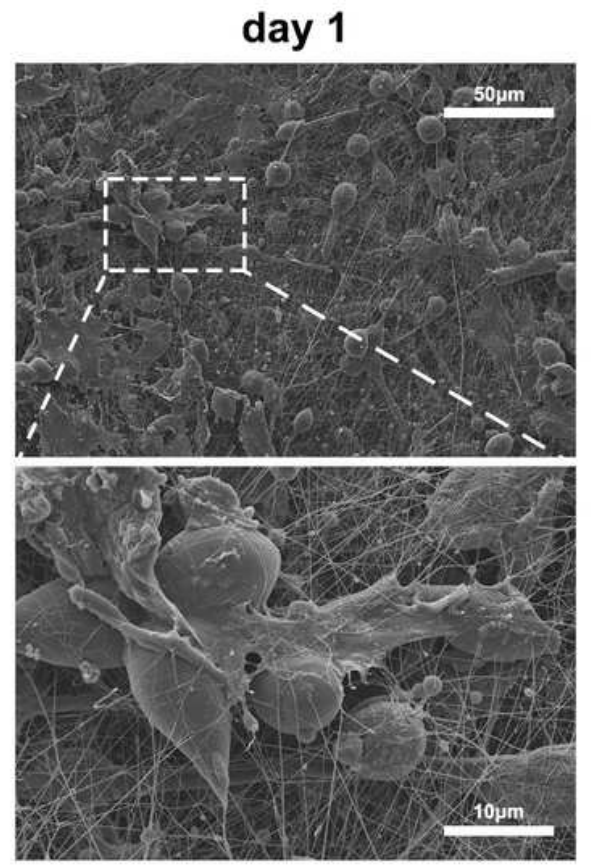

day 4
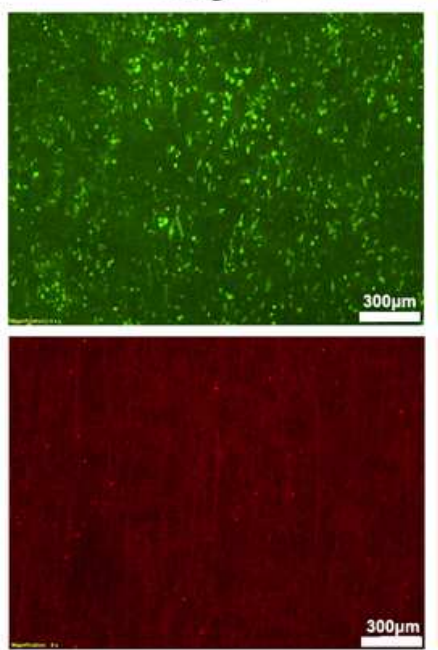

day 7
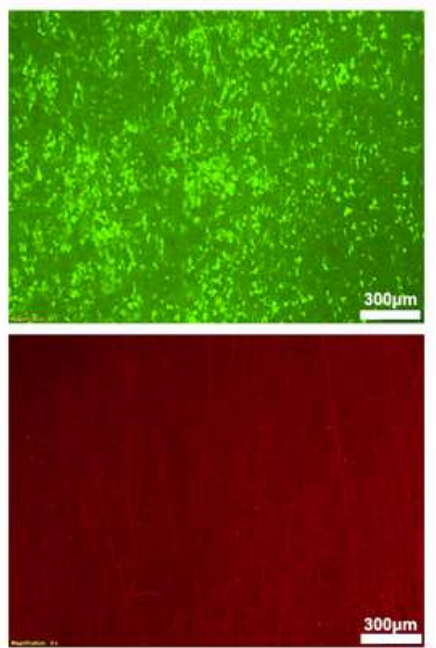

day 4
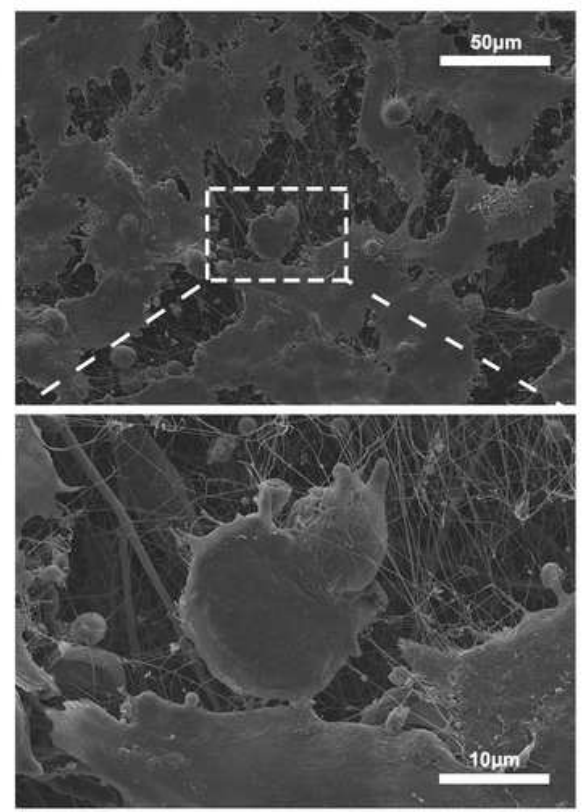

b

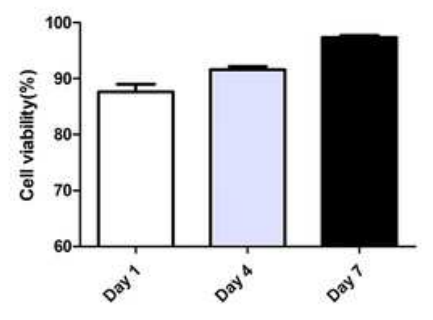

C

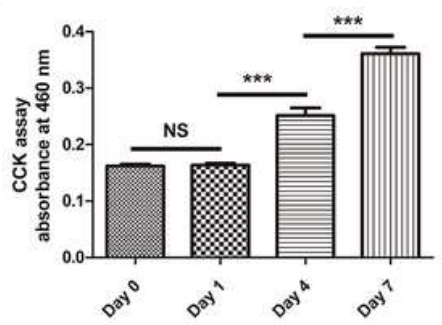

day 7
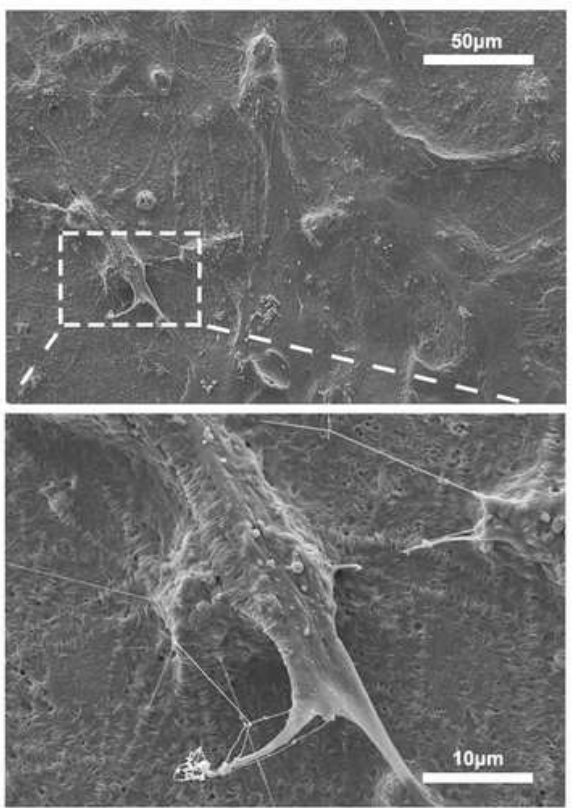

\section{Figure 5}

Viability, proliferation and microstructure of SMCs in GelMA after bioprinting. (a) Live/dead stain of SMCs (Day 1, Day 4, Day 7). (b) Cell viability of SMCs. (Cell survival rate of all groups was more than 90\%) (c) Cell proliferation by CCK-8 assay ( $*, P<0.05$; **, $P<0.01$; NS, not significant, $n=4)$. (d) Microstructure of SMCs in GelMA observed by SEM after seven days of cultivation. 
a
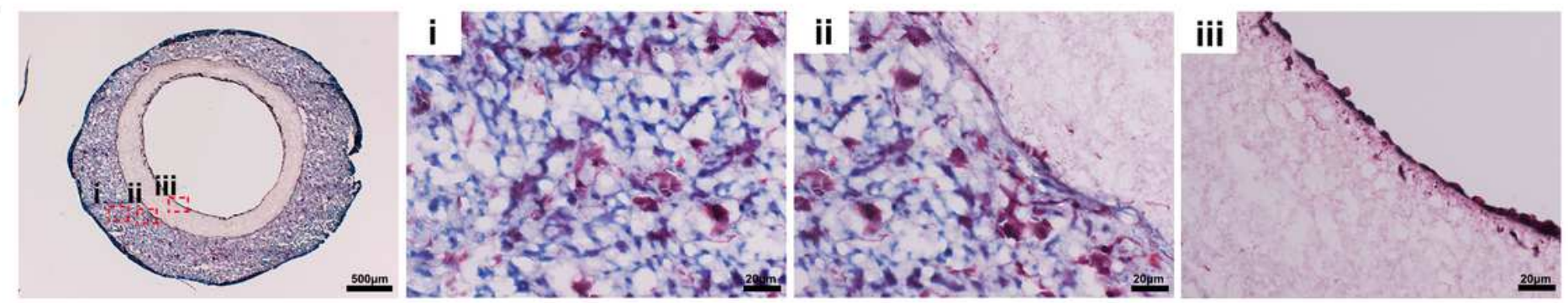

b

DAPI

DAPI/CD 31
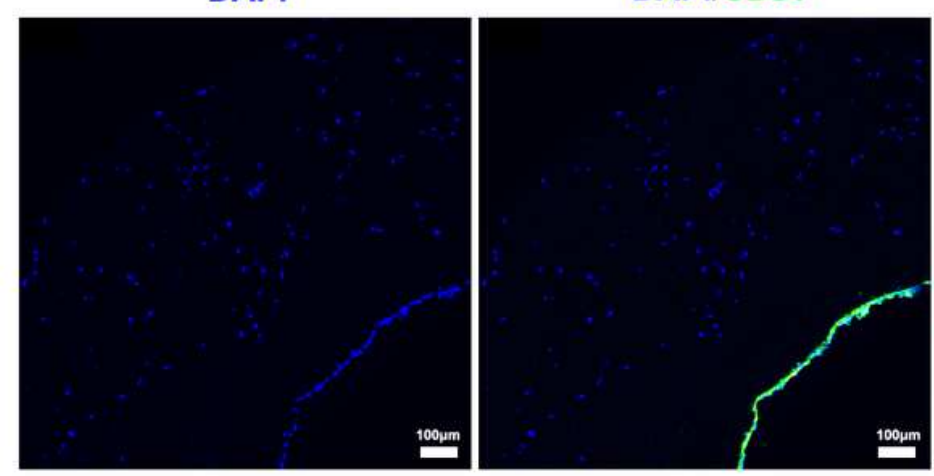

a-SMA/CD31

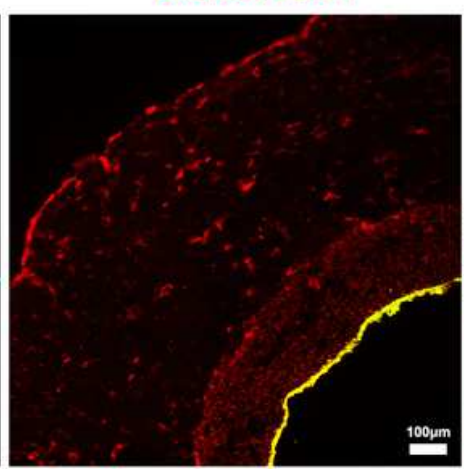

Merge

C

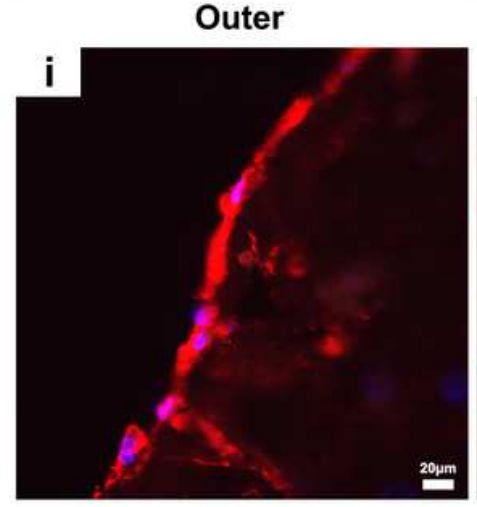

GeIMA
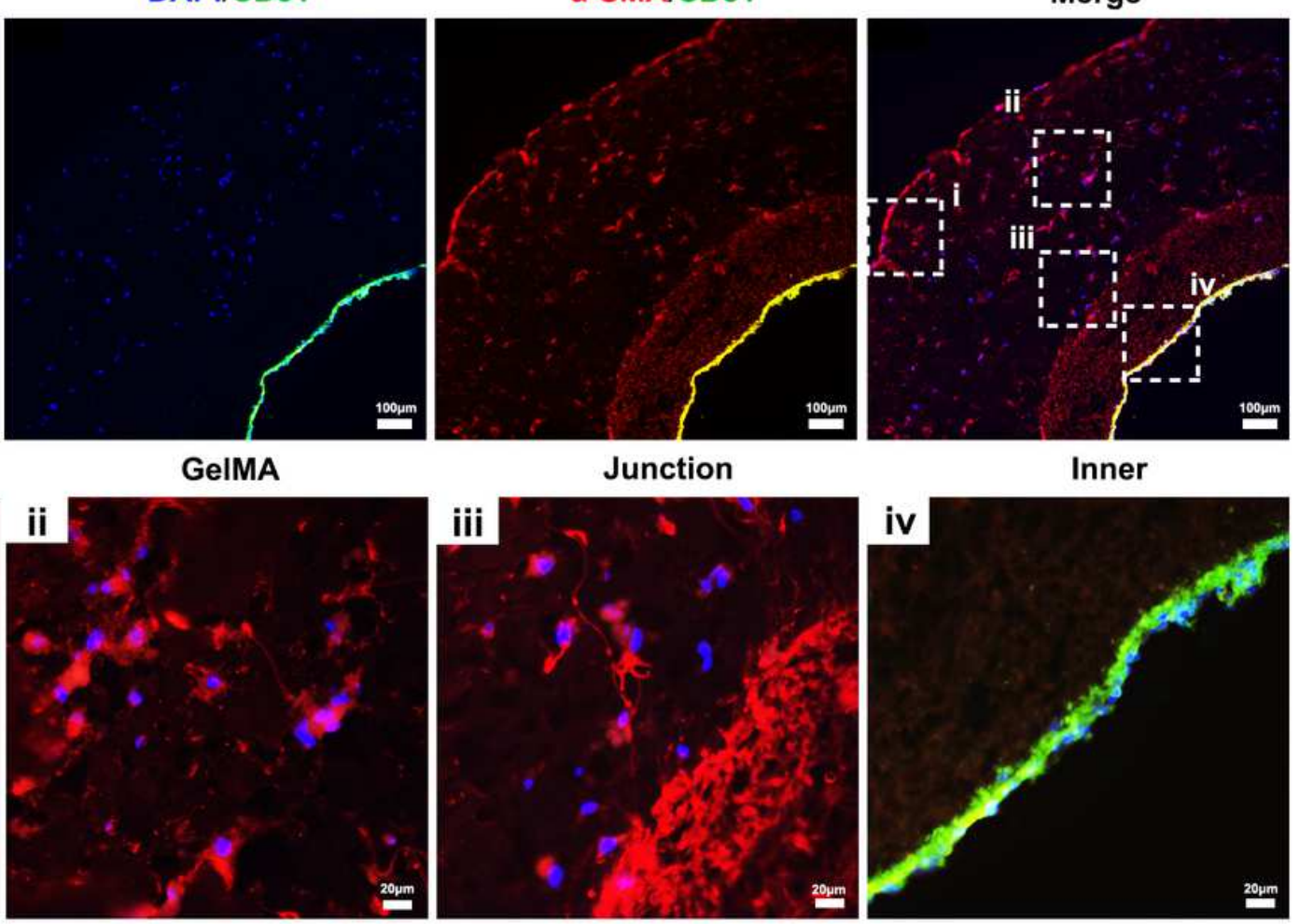

Inner

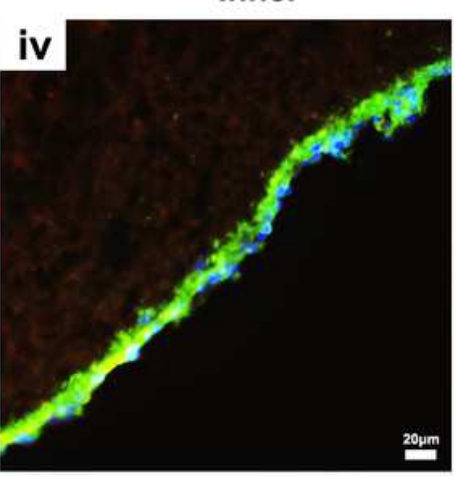

Figure 6

Masson and immunofluorescence staining of bionic vascular tissue. (a) Masson staining: (i) SMCs in GelMA, (ii) Junction, (iii) HUVECs on the surface of fiber. (b) Immunofluorescence of bionic vascular. (CD31, green; a-sma, red; DAPI, blue). (c) Immunofluorescence staining in different positions of bionic vascular tissue: (i) Outer, (ii) GelMA, (iii) Junction, (iv) Inner.

\section{Supplementary Files}

This is a list of supplementary files associated with this preprint. Click to download.

- graphicalabstract1.tif

- support1.tif 